\title{
Changing is not bad
}

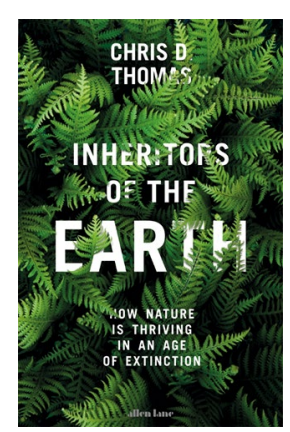

scenery of the ecological gains made from the evolution and development of humans.

This book consists of four parts: introducing and discussing the opportunity and success of certain species in the modern world, the new order of regional diversity as a result of human impact, the dynamic nature of evolution and how humans are accelerating the process, and finally, embracing the new natural world order by being prepared for more changes in the future. A plausible question raised in the book is whether we should treat ourselves as a part of nature or as an independent subject (or even its antithesis). Thomas sides with the idea that humans are the custodians, as well as inmates of the natural world, so that everything created and touched by the development of human society is also a part of natural changes. The effects are extremely complex, with cases such as humans hunting huge mammals to extinction, as well as the boom in domesticated species due to cultivation. The modern transportation system has delivered species all over the world, so in a regional scale it is not uncommon to witness increased diversity. Engineered hybridization and gene communication between species also induce dramatic increases of new species and subspecies, which populate the Earth at a faster rate than ever before. In terms of climate change, Thomas also speculates that the increased $\mathrm{CO}_{2}$ concentration and temperature could increase average biological diversity on a global scale.

Changes are not always bad, because it is just impossible to keep things exactly, or even roughly, as they are. In this book, Thomas encourages us to admit the positive roles of humans in the changing natural world. It is possible, he posits, that we are entering an era of genesis instead of, or perhaps even alongside, an extinction.

Reviewed by Lei Lei

Published online: 3 May 2018 https://doi.org/10.1038/s41477-018-0146-5 